\title{
Identification of the Characteristics That Drive Consumer Liking of Butter
}

\author{
A. J. Krause, K. Lopetcharat, and M. A. Drake ${ }^{1}$ \\ Department of Food Science, Southeast Dairy Research Center, North Carolina State University, PO Box 7624, Raleigh 27695
}

\begin{abstract}
This study identified and explored the sensory characteristics that drive consumer liking of butter. A trained descriptive panel evaluated 27 commercial butters using a defined sensory language. Two focus groups were conducted with butter consumers to gain an understanding of consumer use and consumption habits. Six representative butters and 2 vegetable oil spreads were selected for consumer acceptance testing. Both internal and external preference mapping techniques were applied to interpret consumer data. Key discriminating sensory characteristics of butters included color intensity; diacetyl, cooked, grassy, and milk fat flavors; and salty taste. From focus groups and quantitative consumer testing, the key butter features were a desirable flavor and a natural image. Negative aspects included price and cholesterol. Five consumer clusters with distinct butter and spread flavor likes and dislikes were identified. Butter is a desirable product to consumers. Sensory expectations of butter vary among consumers, and butters with specific sensory characteristics could be marketed to specific target market segments. Key words: butter, flavor, consumer preference, segmentation
\end{abstract}

\section{INTRODUCTION}

Butter is highly prized for its rich flavor attributes. Butter flavor and texture are affected by the type of animal the milk comes from (cow, goat, sheep, etc.); the diet, stage of lactation, and dietary supplementation of the animal; and the season of the year in which it is produced (Hawke and Taylor, 1994; Nickerson, 1995; Bobe et al., 2003; Chen et al., 2004). Additionally, processing, storage conditions, addition of starter culture, and salt contribute to the diverse flavor profile of butter. Most Americans are familiar with sweet cream butter, which is produced without the addition of starter culture, and may or may not have added salt.

Received October 6, 2006.

Accepted January 18, 2007.

${ }^{1}$ Corresponding author: mdrake@unity.ncsu.edu
Butter consumption is currently stagnant; consumption per capita in the United States increased from 4.5 to $4.6 \mathrm{lbs}$ (2.0 to $2.1 \mathrm{~kg}$ ) over the period from 2000 to 2004. Production during this time also remained relatively constant, down only $0.5 \%$ from the 1,256 million pounds ( 570 million $\mathrm{kg}$ ) produced in 2000 (International Dairy Foods Association, 2005). Health concerns have been often been cited as the reason many consumers have decreased their butter consumption and increased their intake of margarine (Crane, 1993). By definition, butter contains $80 \%$ milk fat (USDA, 1989). Margarine and vegetable oil spreads, in contrast, are made from vegetable oil and contain no cholesterol. The legal definition of margarine is that it contains $80 \%$ fat (FDA, 2005). Many softer spreads contain less fat and, by definition, cannot be labeled as margarines. Per capita consumption of margarine in the United States declined between 2000 and 2004, from 7.5 to $5.3 \mathrm{lb} / \mathrm{yr}$ (3.4 to 2.4 kg/yr; USDA-ERS, 2006).

Numerous studies have evaluated consumer acceptance of margarine spreads and butter-oil blends (Hellemann et al., 1990; Michicich et al., 1999; Avramis et al., 2003; Chen et al., 2004; Kim et al., 2005). In contrast, few studies have investigated or compared consumers' perceptions of butter. Crane (1993) used phone surveys to examine consumers' understanding of the health effects, price, taste, and uses of butter and margarine. They reported that over half of the consumers surveyed thought margarine contained less cholesterol and fat and fewer calories than butter. Only one-third of the respondents indicated that price was a factor in their decision to buy butter or margarine. The perception of the spreadability of butter based on color was probed by Rohm et al. (1997). Under normal light, consumers reported that yellow butter was significantly easier to spread than its counterpart, despite both samples having the same instrumental yield value. Under red light conditions, the perception of spreadability was not significantly different.

To our knowledge, no studies have examined consumer attitudes toward the varying flavors exhibited among butters or compared them with margarine or vegetable oil spreads. This study was conducted to iden- 
Table 1. Sensory language used for the descriptive sensory analysis of butter and margarines or spreads

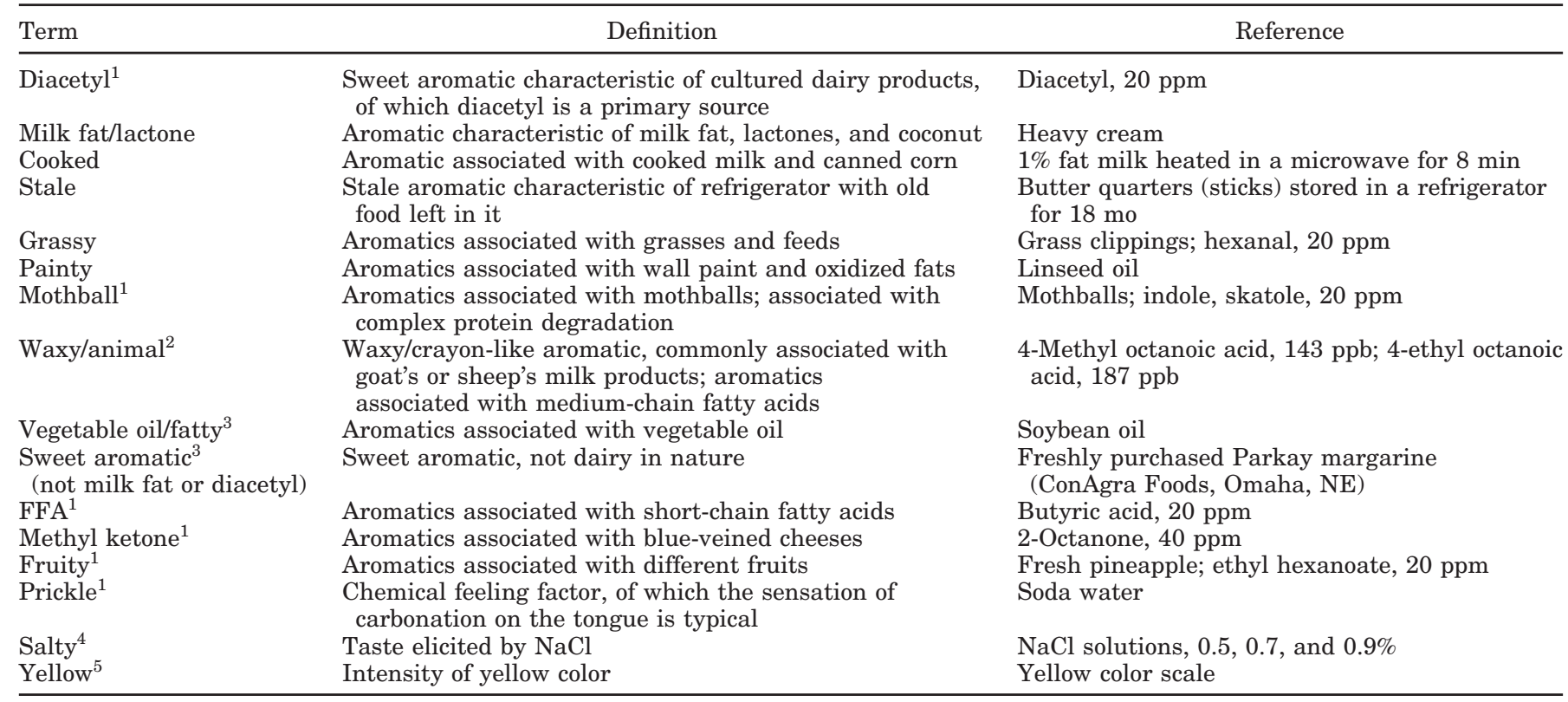

${ }^{1}$ Reference taken from Drake et al. (2001).

${ }^{2}$ Reference taken from Carunchia Whetstine et al. (2003).

${ }^{3}$ Only detected in margarines or spreads.

${ }^{4}$ Reference taken from Meilgaard et al. (1999),

${ }^{5}$ Reference taken from Kornerup and Wanscher (1978).

tify the flavor characteristics that drive consumer acceptance of butter. A descriptive sensory language for butter flavor was identified. This language was then used to document the flavor characteristics of butter and margarines. Consumer acceptance testing was applied, followed by internal and external preference mapping. These results will help manufacturers understand what consumers in different segments of the market prefer and how to best accommodate these market segments.

\section{MATERIALS AND METHODS}

\section{Butter and Margarine Descriptive Analysis}

A descriptive sensory language was first identified to characterize butter flavor attributes. Fifty-six butters were screened and discussed by 5 sensory and dairy experts in three 2-h sessions. Samples included butters aged 1 wk to 2 years as well as cultured, noncultured, salted, unsalted, organic/pasture-fed, domestic, international, and goat and sheep milk butters. A sensory lexicon for butter was created from the terms generated at these sessions. Ten commercial margarines and spreads were subsequently screened by these individuals and 2 terms were added to the lexicon (Table 1).

Twenty-seven representative commercial butters [consisting of international, domestic, freshly produced
( $<72$-h production), aged, cultured, organic/pasture-fed, salted and unsalted, and butters from nonbovine sources] and 2 vegetable oil spreads [one with buttermilk/cultured flavors (60\% fat), and one a traditional margarine-type spread (60\% fat); Table 2] were then evaluated by a trained descriptive panel using the defined sensory language. Commercial products were purchased and stored in the dark at $5^{\circ} \mathrm{C}$ until analysis. The outer $0.3 \mathrm{~cm}$ was trimmed to avoid flavors caused by packaging or exposure. Testing was conducted in accordance with North Carolina State University Institutional Review Board for Human Subjects guidelines.

Nine panelists ( 7 women, 2 men) between 21 and 45 yr of age were selected based on availability and previous experience in the sensory analysis of dairy flavors. All panelists were experienced with the Spectrum method of descriptive analysis ( $>60 \mathrm{~h}$ of experience each) and also participated in $40 \mathrm{~h}$ of additional training on butter and margarine or spread flavor with the identified sensory language (Meilgaard et al., 1999). During training, panelists evaluated and discussed samples to ensure panelist and panel consistency and understanding of the lexicon. Analysis of variance of the data collected from the last part of training indicated that the panel and panelists could consistently use the attributes to differentiate the products.

Sensory analysis of butters and margarines or spreads was conducted by each panelist, in quadrupli- 
Table 2. Butters and spreads used for descriptive analysis ${ }^{1}$

\begin{tabular}{|c|c|c|c|c|}
\hline Treatment & Type $^{2}$ & $\begin{array}{c}\text { Salt } \\
\text { content }^{2}\end{array}$ & Country $^{2}$ & Age \\
\hline 1 & Cultured & Salted & France & Within package date \\
\hline 2 & Sweet cream & Salted & USA & Within package date \\
\hline 3 & Cultured & Unsalted & Italy & Within package date \\
\hline 4 & Sweet cream & Salted & USÅ & Within package date \\
\hline 5 & Cultured & Unsalted & USA & Within package date \\
\hline 6 & Sweet cream & Unsalted & USA & Within package date \\
\hline 7 & Cultured & Unsalted & Denmark & Within package date \\
\hline 8 & Cultured & Salted & USA-Southeast & Within package date \\
\hline 9 & Sweet cream & Unsalted & USA & Within package date \\
\hline 10 & Sweet cream & Salted & USA & Within package date \\
\hline 11 & Sweet cream & Salted & England & Within package date \\
\hline 12 & Goat's milk cultured & Salted & France & Within package date \\
\hline 13 & Cultured & Unsalted & Spain & Within package date \\
\hline 14 & Cultured & Salted & USA-Southeast & Within package date \\
\hline 15 & Sweet cream & Unsalted & Australia & Within package date \\
\hline 16 & Sweet cream & Salted & Ireland & Within package date \\
\hline 17 & Sheep's milk cultured & Unsalted & Greece & Within package date \\
\hline 18 & Sweet cream & Salted & USA-West coast & Within package date \\
\hline 19 & Sweet cream & Salted & USA & $24 \mathrm{mo}$ at $5^{\circ} \mathrm{C}$ \\
\hline 20 & Cultured & Unsalted & New Zealand & Within package date \\
\hline 21 & Cultured & Unsalted & USA-Northeast & Within package date \\
\hline 22 & Sweet cream & Salted & France & Within package date \\
\hline 23 & Sweet cream & Salted & USA-Midwest & Within package date \\
\hline 24 & Sweet cream & Salted & USA-West coast & Within $48 \mathrm{~h}$ of production \\
\hline 25 & Sweet cream & Salted & USA-West coast & 15 mo at $5^{\circ} \mathrm{C}$ \\
\hline 26 & Cultured & Salted & USA-Northeast & Within package date \\
\hline 27 & Sweet cream & Salted & USA & Within package date \\
\hline 28 & $70 \%$ vegetable oil & Salted & USA & Within package date \\
\hline 29 & $70 \%$ vegetable oil & Salted & USA & Within package date \\
\hline
\end{tabular}

cate replications, in a randomized balanced design. Panelists individually evaluated 7-g samples presented in 2-oz. (59-mL) plastic cups with plastic lids (Sweetheart Cup Co., Owings Mills, MD) in sensory booths. All sample cups were labeled with a 3-digit code and samples were tempered to $19^{\circ} \mathrm{C}$. This temperature was chosen because panelists could best detect subtle differences in flavor when samples were tempered to this temperature. Panelists evaluated 6 samples per session and were given room-temperature deionized water and unsalted crackers to cleanse their palates between samples.

\section{Focus Groups}

Two focus groups ( 8 females, ages 24 to $40 \mathrm{yr}$, and 8 females $>46 \mathrm{yr}$ ) were conducted to gain a better understanding of butter and margarine or spread use and consumption habits. A screening form was filled out by the participants to obtain demographic information and background information on their butter and nonbutter spread use. Focus groups lasted approximately $1.5 \mathrm{~h}$.

An experienced moderator asked the participants a series of predetermined questions in a round-table format. Subjects were first asked about their habits of butter and of margarine or spread consumption (frequency, on what occasions, etc.). Attitudes on health and use were probed and the brand and type of butter used (salted vs. unsalted) were also discussed.

Toward the end of the discussion, subjects were given tempered $\left(19^{\circ} \mathrm{C}\right)$ samples of stick margarine, spreadable (tub) margarine, stick butter, and spreadable butter to evaluate and discuss. All samples were identified by a 3 -digit code. Color, texture (spreadability, hardness, etc.), and flavor of the samples were discussed. Following this evaluation, participants were given the same 4 samples with labels that indicated the type of sample and brand. Attitudes toward the brands were discussed. Focus group sessions were videotaped and tape-recorded for subsequent reference. Key points from the focus group sessions (those issues mentioned by two-thirds or more of participants) were used to develop the consumer questionnaire and ballot.

\section{Consumer Testing}

Based on the descriptive sensory data means and examination of the principal components (PC) plots, 6 representative butters were selected for consumer testing based on the attributes of salty taste, diacetyl, 
cooked, yellow color, grassy, mothball, and stale flavors. These were flavors or attributes that were prevalent in all butters or flavors that would be encountered in specific types of butters commonly available in the United States. Other flavors that differentiated the butters (methyl ketone, fruity, waxy/animal, FFA) were not selected because they did not represent butters that would be commonly encountered by the US consumer (goat and sheep milk butters) and butters that were available in limited quantities. Two vegetable oil spreads (60\% vegetable oil) were included; one represented a typical salted stick spread and one represented a cultured, butter-flavored vegetable-oil stick spread.

Samples $(7 \mathrm{~g})$ were placed into 2 -oz. $(59-\mathrm{mL})$ plastic cups with plastic lids (Sweetheart Cup Co.), numbered with a 3-digit code, and tempered to $19^{\circ} \mathrm{C}$. Our study was focused on butter flavor, and we wished to minimize the impact of spreadability because vegetable oil spreads were also presented. Further, some focus group participants had indicated that they stored butter at room temperature and consumed it at this temperature. Samples were evaluated individually in sensory booths and were presented in a randomized balanced order. Butter consumers were recruited via e-mail, classified advertisements, and flyers. To qualify for participation, consumers had to be self-reported consumers of butter, although butter did not have to be the sole fat source consumed, nor was frequency of consumption an issue. All participants were screened for allergies to dairy products. Testing was conducted in accordance with the North Carolina State University Institutional Review Board for Human Subjects guidelines. Subjects were given ambient-temperature deionized water to cleanse their palates between samples. Compusense version 5.0 (Compusense, Guelph, Ontario, Canada) was used for data collection.

Demographic information was collected, as well as information on butter and spread use. Additionally, panelists were asked about the occasions on which they used butter and margarine or spreads, how often they used them, what factors affected their purchases, whether they viewed butter and margarine or spreads as natural, and whether they viewed butter as healthier than margarines or spreads. For the last 2 categories of questions, consumers were provided with the statements "Butter (or margarine) is a natural product" and "Butter is healthier than margarine." Consumers were then asked to indicate how they felt about each statement (agree strongly, agree, neither agree nor disagree, disagree, disagree strongly).

During the sample evaluation, panelists were instructed to spread the sample on a piece of white pita bread (previously screened and determined to be bland by the trained panel; Neomonde Bakery, Raleigh, NC).
White pita bread was chosen because it could be obtained freshly made (within $48 \mathrm{~h}$ ) prior to the test and was bland, allowing the maximum flavor impact of the butter or spread to be evaluated. Participants were asked to evaluate overall acceptance, appearance liking, color intensity, color liking, salty taste intensity, salty taste liking, freshness intensity, texture liking, and flavor liking. All attributes were evaluated using a 9-point hedonic scale in which "like extremely" ( score = 9) and "dislike extremely" (score = 1) were used for liking attributes and "high intensity" ( and "low intensity" (score $=1$ ) were used for intensity attributes. Subjects received food treats and a gift certificate for their participation.

\section{Statistical Analysis}

Univariate and multivariate techniques were used to analyze the data. Statistical analysis of the descriptive data was conducted using SAS (version 9.2, SAS Institute, Cary, NC). Analysis of variance with separation of means (Fisher's least significant difference) and PC analysis (PCA) with Varimax rotation of descriptive data were performed to identify characteristic differences between the samples. Analysis of variance with separation of means, and internal preference mapping (PCA of consumer liking data) were conducted on consumer data (version 9.2, SAS Institute). Frequency counts were tabulated for consumer demographic, habit, and attitude information. The Pearson $\chi^{2}$ test was used to identify significant associations and trends among demographic, habit, and attribute information and identified consumer segments. These analyses were performed using SPSS version 12.0 (SPSS Inc., Chicago, IL).

Partial least squares regression 2 (PLS2) was used to construct external preference maps. The PLS2 focuses on explaining the variation in $y$-variables (consumer-liking matrix; 8 products, 161 consumers) by using the descriptive sensory results (Martens and Martens, 2001; Biasioli et al., 2006). Important descriptive attributes were identified using the jackknife method. The PLS2 and jackknife optimization methods were performed using The Unscrambler version 9.2 (CAMO, Oslo, Norway). Two attributes [vegetable oil/fatty and sweet aromatic (not dairy)] that were exclusively associated with margarines or spreads as well as the attributes waxy/animal, fruity, and methyl ketone, which were not present in the butters used for consumer testing, were excluded from the analysis because the attributes did not contribute any variation in the data set.

A two-step cluster analysis (TCA) was performed on individual consumer coordinates within the preference space generated by PLS2. The TCA was performed us- 
Table 3. Means separation for descriptive analysis of commercial butters and spreads ${ }^{1}$

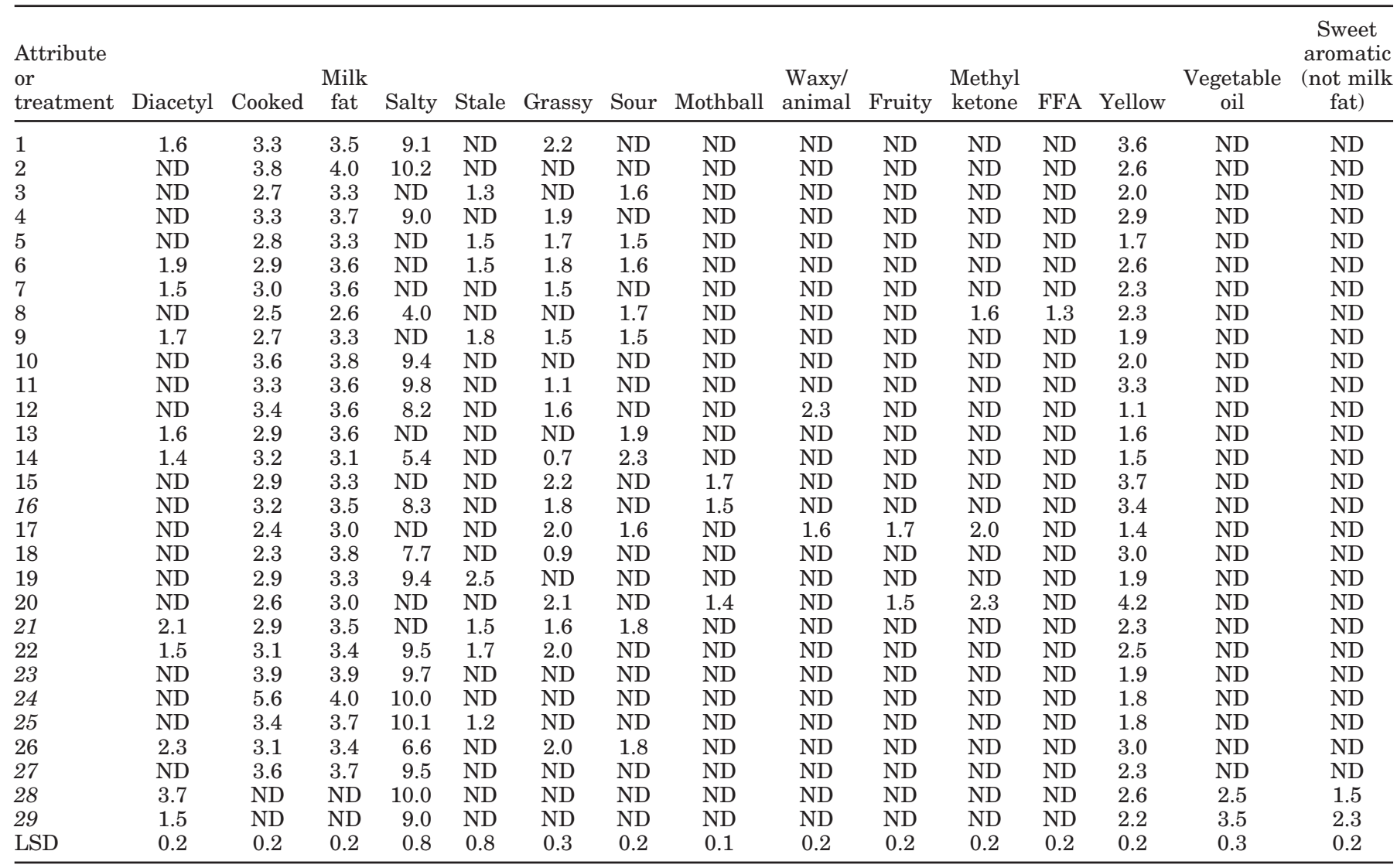

${ }^{1}$ Italicized products were used for consumer testing. ND = not detected. Painty and prickle were not detected in any of the samples. Attributes were evaluated by trained panelists using the 15-point universal Spectrum intensity scale, where $1=$ very low intensity and 15 = highest possible intensity (Meilgaard et al., 1999). Means within a column that differ by more than the LSD are different $(P<0.05)$.

ing log-likelihood as a distance measure, and the number of segments was automatically determined using the combination of changes in Akaike's information criterion and the greatest changes in the distance when clusters were divided sequentially (Banfield and Raftery, 1993; Zhang et al., 1996; Chiu et al., 2001; SPSS, Inc., 2001). A discriminant analysis with cross-validation was used to confirm and determine final segmentation from the TCA with at least $95 \%$ correct allocation. The TCA and discriminant analysis were performed using SPSS version 12.0 (SPSS, Inc.).

After segmentation, the liking profiles for each segment were generated. Means of liking attributes were estimated using 2-way ANOVA without an interaction term $($ consumer $=$ random effect; sample $=$ fixed effect $)$. Tukey's honestly significant differences multiple comparisons were performed on the significant sample effect for each liking attribute at the $95 \%$ confidence level. A PCA was performed to study correlations between overall liking and other attribute likings to gauge important aspects of butter and margarine. The analysis was performed on the whole data set and within each segment using maximum likelihood extraction and Varimax rotation. The PCA and ANOVA were performed using SPSS version 12.0 (SPSS, Inc.).

\section{RESULTS AND DISCUSSION}

\section{Descriptive Analysis}

The sensory language identified differentiated the butters and spreads (Table 3). Principal components plots of butters are shown in Figures 1 and 2. Principal component 1 (28\% variability) was composed of waxy, fruity, and methyl ketone flavors, whereas PC2 (21\% variability) differentiated the butters on grassy and mothball flavors and yellow color intensity. Principal component 3 (16\% variability) differentiated the butters on cooked, milk fat, and salty taste (positively loaded) and stale flavor (negatively loaded). Principal component 4 (10\% variability) was composed of cultured butter flavors (diacetyl flavor and sour taste). Two terms, painty and prickle, were identified in the butters used for language generation but were not identified in the samples used in this study. 


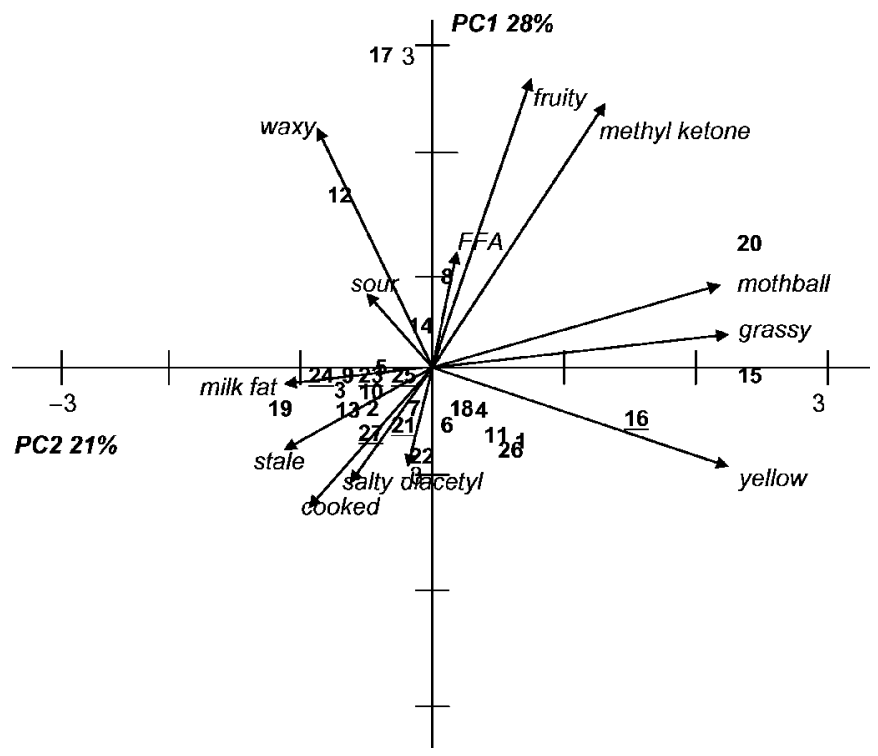

Figure 1. Principal components biplot of descriptive sensory analysis of commercial butters. Numbers represent samples (Table 2). Underlined numbers represent those chosen for consumer testing. $\mathrm{PC} 1=$ principal component $1 ; \mathrm{PC} 2=$ principal component 2 .

Other attributes were identified in a few samples. Waxy/animal was identified only in butters made from goat's or sheep's milk. Methyl ketone, FFA, and mothball were also documented in a few of the international samples. Other terms were associated with butter types. Sour taste and diacetyl were associated with cultured butters. The 2 nonbutter spreads had very dis-

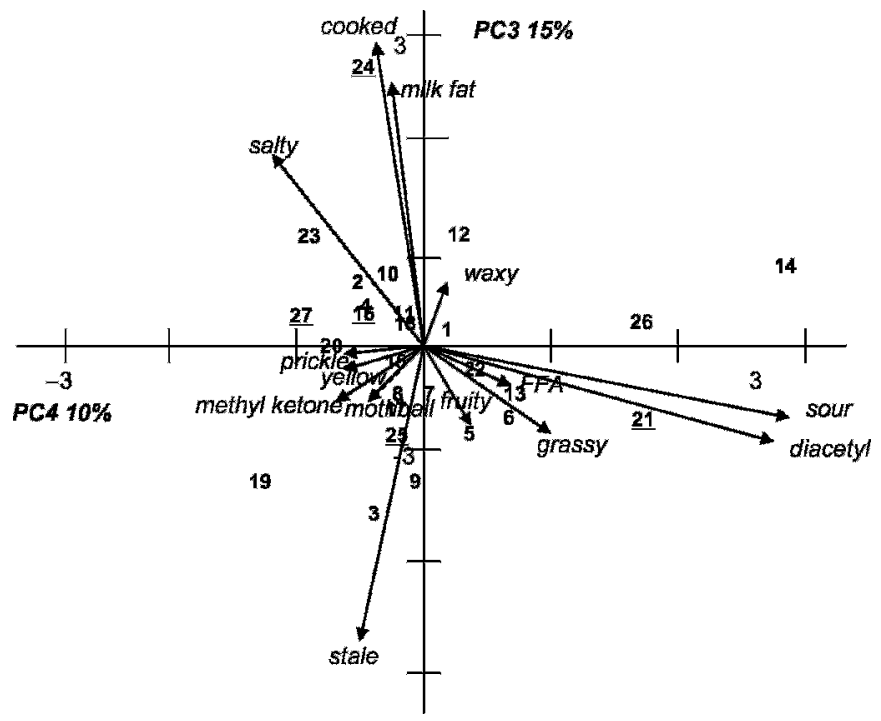

Figure 2. Principal components biplot of descriptive sensory analysis of commercial butters. Numbers represent samples (Table 2). Underlined numbers represent those chosen for consumer testing. PC3 = principal component $3 ; \mathrm{PC} 4=$ principal component 4 . tinct sensory profiles, which differentiated them from the other butters (Table 3 ). They were characterized by distinct intensities of vegetable oil/fatty and nondairy sweet aromatic. These flavors were not detected in the butters. Clearly, butters represent a wide range of flavor characteristics. Similar descriptive techniques have been used to differentiate other products, including cheese, peanut butter, and chocolate milk, among others (McNeill et al., 2002; Thompson et al., 2004; Young et al., 2004).

\section{Focus Groups}

Participants indicated that they used butter several times a week or sparingly. Those who used it sparingly consumed margarines or spreads on a regular basis and used butter only for special occasions. For both groups, we noted that consumers appeared to fall primarily into 2 groups: butter-only consumers, and margarine + butter consumers. Individuals who consumed margarine on a regular basis quite often used butter for special occasions or for baking.

Many of the older participants ( $>46 \mathrm{yr}$ ) indicated that the negative health aspects of butter (high fat, cholesterol, and calories) were deciding factors in their purchase and consumption of butter. The younger group (24 to $40 \mathrm{yr}$ ) were generally not concerned with the health aspects of butter, and butter was viewed as about as healthy as margarine. The consensus among these consumers was that butter and margarine were best consumed in moderation. Similarly, participants in focus groups carried out by Wright (1991) preferred the taste of butter but were concerned about health issues associated with it. Likewise, Crane (1993) found that $69 \%$ of consumers surveyed over the telephone agreed that they preferred the taste of butter to margarine. Crane also found that $93 \%$ of participants said that concern over health influenced their butter vs. margarine purchase decision.

Although the consumers surveyed by Crane agreed (86\%) that butter was more expensive than margarine, only $36 \%$ said that price influenced their purchase decision. In this study, many focus group subjects considered price a factor in their purchase decision, as did a majority of the participants in our quantitative consumer test $(60 \%$ of butter-only consumers and $72 \%$ of butter + margarine consumers; Table 4). Many participants in the younger group viewed butter as a natural product. Across both focus groups, most women indicated they preferred butter for baking uses, because it was prized for its flavor. This observation is in contrast to previous studies using focus groups in which participants indicated that they used butter for everyday uses 
Table 4. Gender, age, and butter and spread consumption characteristics of consumers

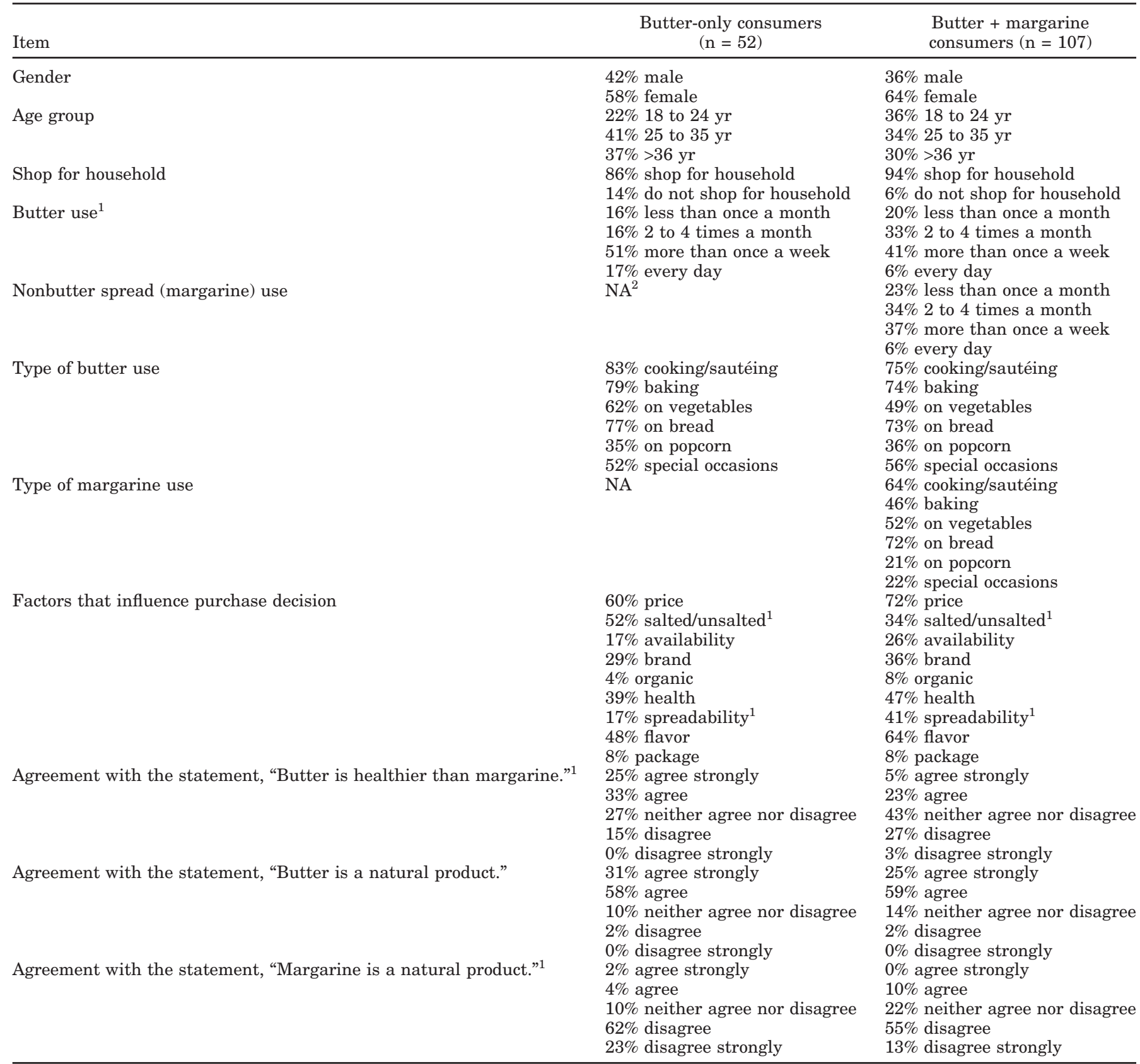

${ }^{1}$ Indicates differences between the 2 groups $(P<0.05)$.

${ }^{2} \mathrm{NA}=$ not applicable.

and margarine in baking applications (Wright, 1991; Crane, 1993).

The majority of participants indicated that margarine has a distinctive odor and a deeper yellow color than butter. A light yellow color was deemed desirable for butter. Butter was more difficult for the subjects to spread. The majority of subjects preferred the taste of butter over margarine. It is important to note that results from the focus groups provided qualitative obser- vations from a small number of participants. We compared these results with previously published focus group research and then used our results as a guide in preparing our consumer screening form, ballots, and samples.

\section{Consumer Results}

Consistent with the focus group results, consumers primarily fell into 2 groups: butter-only $(\mathrm{n}=52)$, and 
Table 5. Consumer acceptance scores for commercial butters and spreads ${ }^{1}$

\begin{tabular}{|c|c|c|c|c|c|c|c|c|c|}
\hline $\begin{array}{l}\text { Attribute or } \\
\text { treatment }\end{array}$ & $\begin{array}{c}\text { Overall } \\
\text { acceptance }\end{array}$ & $\begin{array}{l}\text { Appearance } \\
\text { liking }\end{array}$ & $\begin{array}{c}\text { Color } \\
\text { intensity }\end{array}$ & $\begin{array}{l}\text { Color } \\
\text { liking }\end{array}$ & $\begin{array}{c}\text { Salty } \\
\text { intensity }\end{array}$ & $\begin{array}{c}\text { Salty } \\
\text { taste liking }\end{array}$ & $\begin{array}{l}\text { Freshness } \\
\text { intensity }\end{array}$ & $\begin{array}{l}\text { Texture } \\
\text { liking }\end{array}$ & $\begin{array}{l}\text { Flavor } \\
\text { liking }\end{array}$ \\
\hline 16 & 5.6 & 5.3 & 7.4 & 5.1 & 5.3 & 5.7 & 5.5 & 5.7 & 5.5 \\
\hline 21 & 4.6 & 6.2 & 4.9 & 6.0 & 3.0 & 4.1 & 5.1 & 5.6 & 4.3 \\
\hline 24 & 5.8 & 6.3 & 4.6 & 6.1 & 4.9 & 5.5 & 6.0 & 6.4 & 5.7 \\
\hline 25 & 5.8 & 6.2 & 4.5 & 5.9 & 5.6 & 5.5 & 5.9 & 6.2 & 5.7 \\
\hline 27 & 5.1 & 6.3 & 5.6 & 6.0 & 5.3 & 5.2 & 5.3 & 6.0 & 4.8 \\
\hline
\end{tabular}

${ }^{1}$ Products were scored using a 9 -point scale, where $1=$ low intensity/dislike extremely and $9=$ high intensity/like extremely. Means in a column that differ by more than the LSD are different $(P<0.05)$.

butter + margarine $(n=107)$ consumers. Two of the 161 consumers polled were margarine-only consumers. Their results were excluded from analysis. For certain items, the user category influenced consumer use and perception (Table 4). The presence or absence of salt and spreadability influenced purchase decisions differently for the 2 user groups $(P<0.05)$. The presence or absence of salt played a larger role in the purchase decision for butter-only users, whereas, not surprisingly, spreadability played a larger role for the butter + margarine consumers $(41 \%$ compared with $17 \%$, respectively, $P$ $<0.05)$.

Butter-only users were generally in greater agreement that "Butter is healthier than margarine," compared with butter + margarine users (Table 4). The majority of both butter-only and butter + margarine users either strongly agreed or agreed that butter is a natural product (88 and $84 \%$, respectively; Table 4). In contrast, more butter + margarine users than butteronly users were either more positive or neutral about the statement "Margarine is a natural product" $(P<$ $0.05)$. These results are in agreement with our focus group results, in which participants were generally knowledgeable about nutritional differences between butter and margarine. Crane (1993) found that consumers were not well informed about the differences between butter and margarine, including hydrogenation and trans fat content. The shift in knowledge of trans and saturated fat content may be due to recently implemented regulations by the FDA requiring labeling of trans fats (FDA, 2003) and more attention being paid to saturated and trans fats and their negative health consequences. This natural image of butter is an attribute consumers value and one that manufacturers should emphasize. The market for less-processed and natural foods is among the fastest growing market segments, according to a report by the Agricultural and Marketing and Research Center (Norwood, 2004).

Overall, consumers indicated distinct differences and likings for butters and margarines (Table 5 and Figure
3). Product 23 was the most well-liked product. This product was a domestic sweet cream butter that is nationally marketed. Perhaps not surprisingly, it was the most well liked when averaged across all consumers. Products 21, 27, and 28 scored the lowest overall acceptance scores. Product 28 was a vegetable oil spread, and products 21 and 27 were unsalted and salted butters, respectively. Examination of the descriptive data did not reveal any common attributes among these 3 products.

\section{External Preference Mapping}

External preference mapping using PLS analysis was applied to further explore consumer likes and dislikes

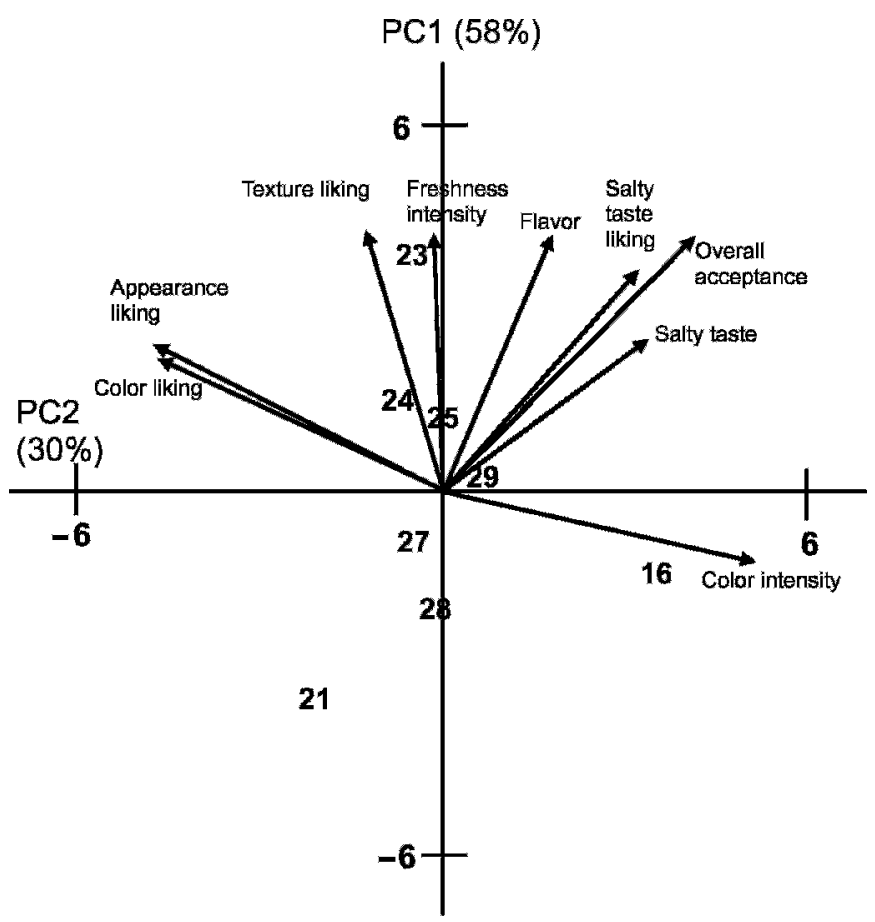

Figure 3. Internal preference map of consumer results. Numbers represent samples $($ Table 2$)$. $\mathrm{PC} 1=$ principal component $1 ; \mathrm{PC} 2=$ principal component 2 . 


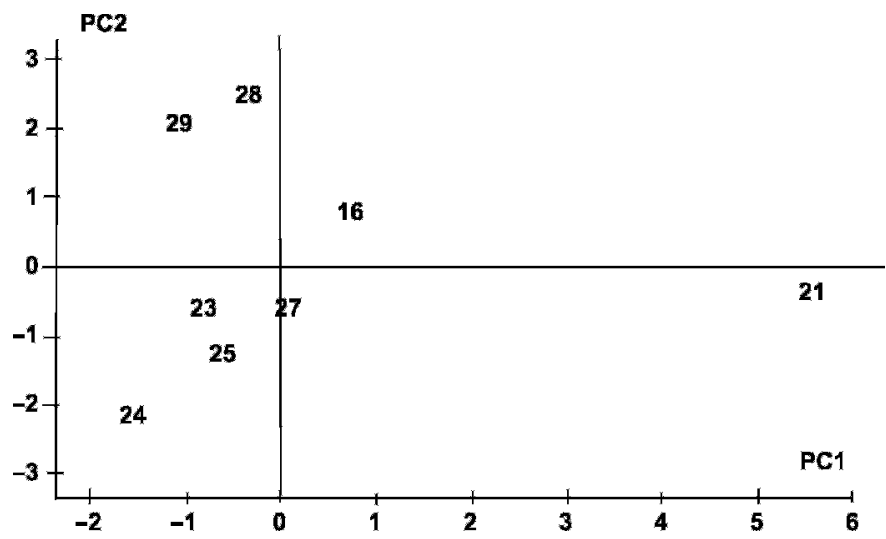

Figure 4. Partial least squares model of consumer scores. Loading plot of principal component 1 (PC1) vs. PC2. Principal component 1 explains 40\%; PC2 explains 20\%. Numbers indicate samples (Table 2 ). Different samples (by consumers) are located far apart from each other.

for the butters and vegetable oil spreads. External preference mapping regresses individual consumer preferences onto the $\mathrm{PC}$ of the covariance matrix of descriptive or other analytical ratings across products (Schlich, 1995). The dimensions of the descriptive analysis space are the predictor variables, whereas consumer acceptability is the response variable (Schlich, 1995). The PLS sample liking scores are presented in Figures 4 and 5 and the loadings of the descriptive sensory attributes that are predictive for liking are presented in Figures 6 and 7. A TCA was then applied to these results to identify specific consumer groups more clearly. This analysis yielded 5 distinct preference segments among butter and margarine consumers (Figure 8). For a specific preference segment of interest, such as segment 1 ,

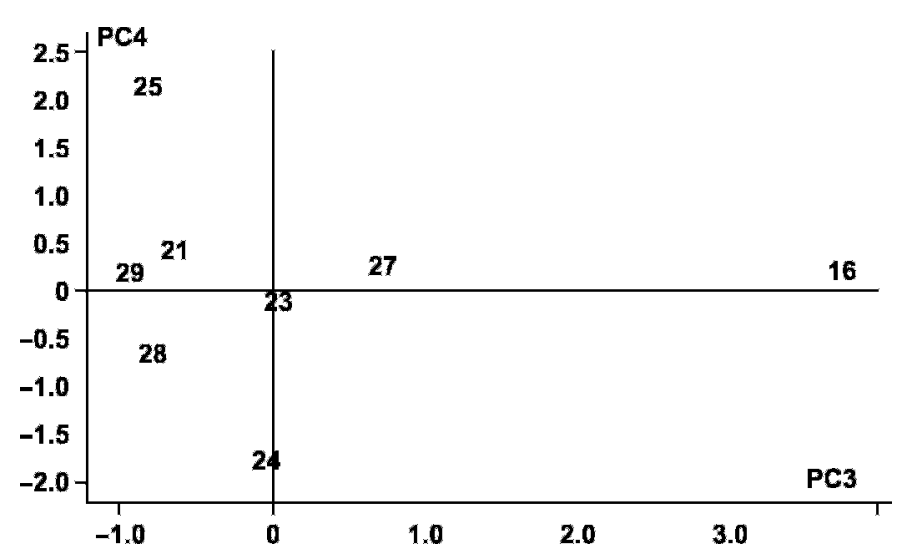

Figure 5. Sample partial least squares model of consumer scores. The loading plot of principal component 3 (PC3) vs. PC4. Principal component 3 explains 19\%; PC4 explains $12 \%$. Numbers indicate samples (Table 2). Different samples are located far apart from each other.

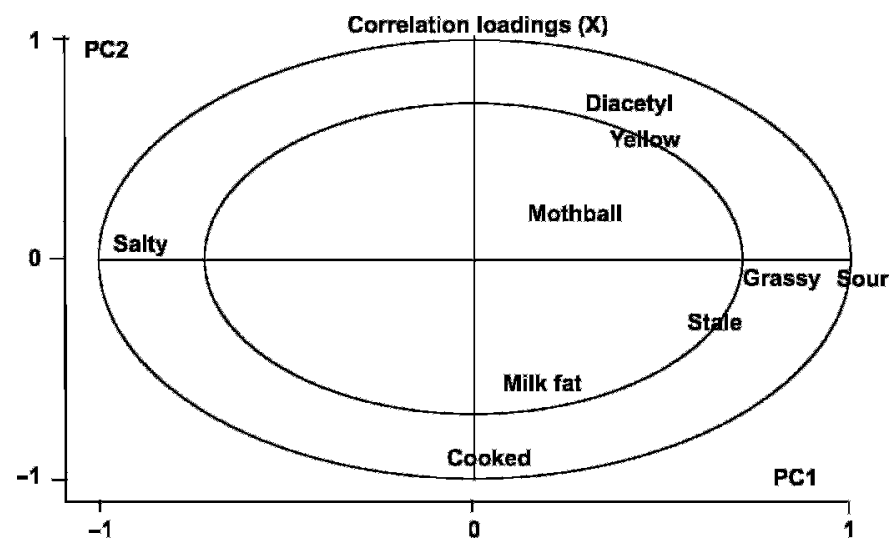

Figure 6. Correlation biplot of descriptive attributes using the partial least squares model. Principal component 1 (PC1) explains 40\%; PC2 explains 20\%. Attributes are descriptive attributes (Table 1 ). The strength of the correlation is indicated by the distance from the origin. The inner ellipse indicates $50 \%$ variance and the outer ellipse indicates $100 \%$ variance.

the location of the most well-liked products (23 and 25) can be seen in Figures 4 and 5, with companion plots (Figures 6 and 7, respectively) to aid in identifying the driver(s) of liking. Figures 6 and 7 are plots of the correlations of the descriptive attributes in the sensory space of Figures 4 and 5. Therefore, the descriptors loading in the direction of the most well-liked products (for segment 1, products 23 and 25 ) would be interpreted as the drivers of liking for consumers in this particular segment. The same can be done with each consumer segment for drivers of liking and with the least wellliked products to infer what consumers did not like.

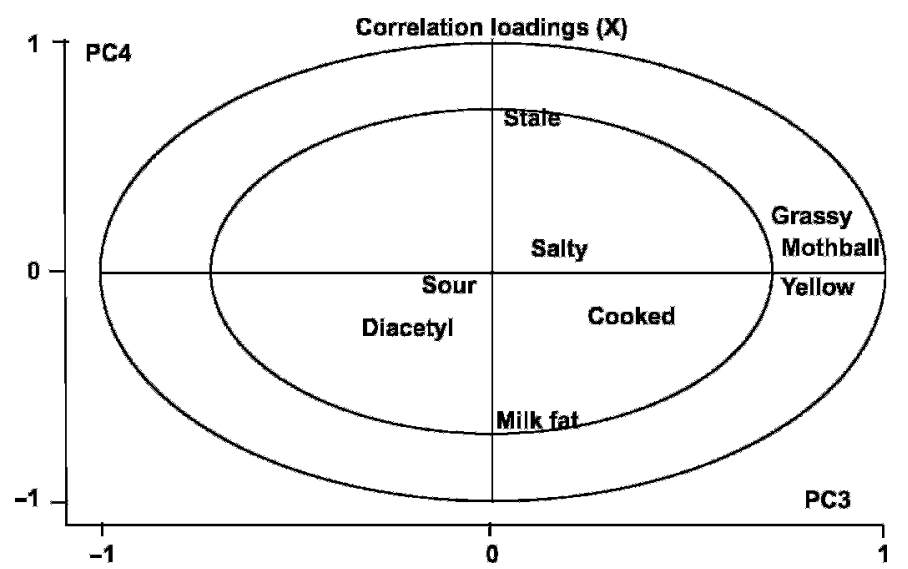

Figure 7. Correlation biplot of descriptive attributes using the partial least squares model. Principal component 3 (PC3) explains 19\%; PC4 explains 12\%. Attributes are descriptive attributes (Table 1 ). The strength of the correlation is indicated by the distance from the origin. The inner ellipse indicates $50 \%$ variance and the outer ellipse indicates $100 \%$ variance. 


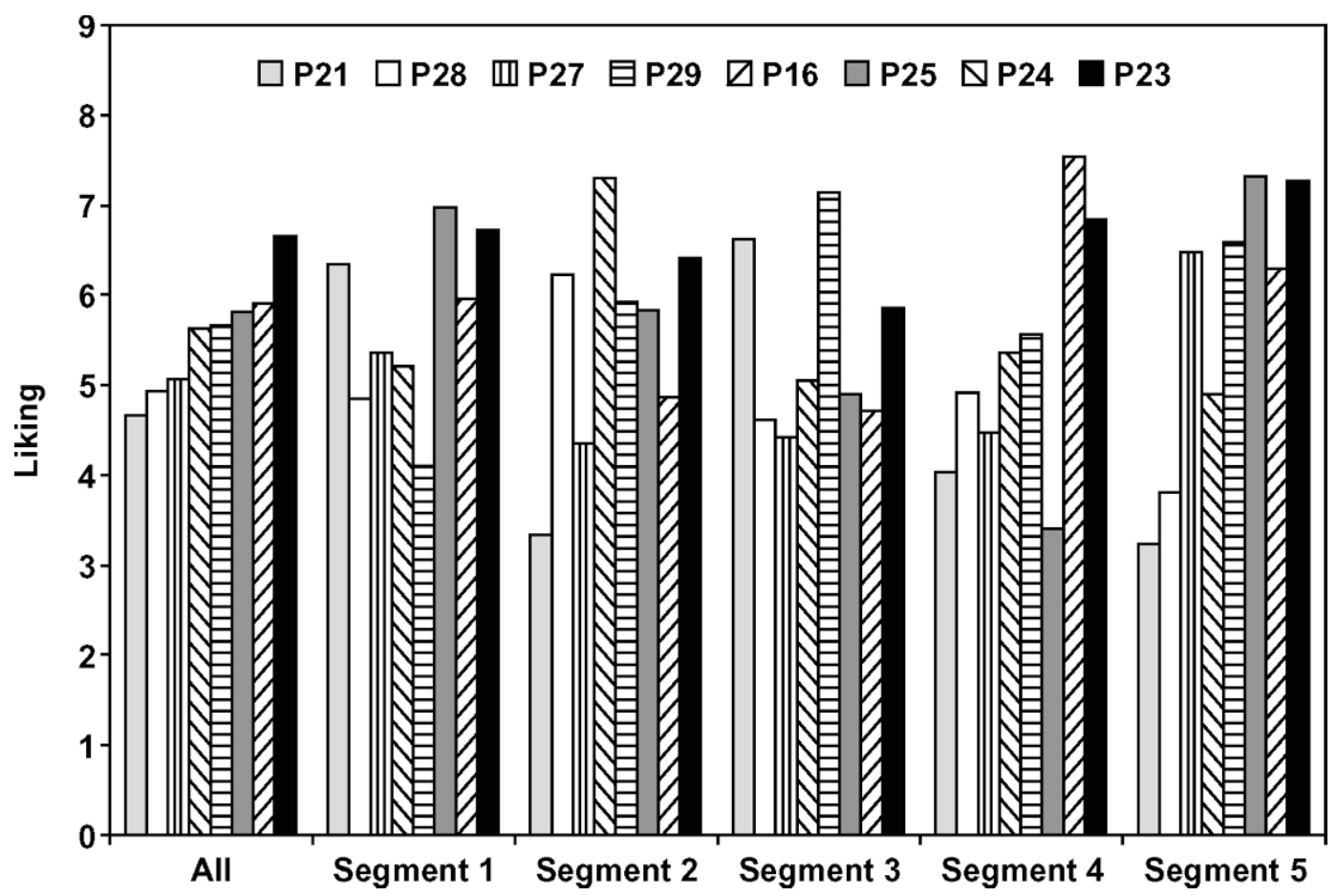

Figure 8. Overall acceptability scores for butter and spreads within different consumer segments. Acceptability was scored based on a 9 -point hedonic scale where 1 = dislike extremely and $9=$ like extremely. $\mathrm{P}=$ product.

Segment $1(n=42)$ contained traditional butter lovers. This was where the largest number of butter-only consumers was found $(\mathrm{n}=21)$. These consumers liked traditional butter flavors: Cooked, milk fat, and even stale flavors were acceptable. The presence or absence of salt did not matter. Margarines, yellow color, and unusual butter flavors such as grassy were not desirable. The top 2 butters for these consumers were products 23 and 25 .

Segment $2(n=34)$ contained primarily margarine lovers. The largest number of margarine and butter users was found in this segment $(\mathrm{n}=29)$. The traditional vegetable oil spread (product 29) was their favorite. Their next choice was essentially a tie between traditional butter (product 23) and "butter-style" margarine (product 28). These consumers liked the unsalted butter least by a wide margin. Moskowitz (2001), who examined drivers of margarine liking, was able to segment participants into 2 groups based on attributes that were desirable for margarine consumption. The first group was identified as liking a lighter color, an intermediate flavor strength, and an intermediate softness in texture. The second segment of margarine consumers was composed of consumers who liked darker colors, stronger flavors, and a very soft texture. The "margarine lovers" (segment 2) in our study appeared to fit into the second group described by Moskowitz
(2001). Segment 2 rated the softest textures and darkest colors (vegetable oil spreads and product 16) as the most desirable.

Consumers in segment $3(\mathrm{n}=21)$ preferred butters with unusual flavors. Salt was not a driver. Butters with a high yellow color and grassy, mothball, or stale flavor were their preferred butters. Their favorite butters were products 16 and 21. Particular or discerning butter consumers comprised segment $4(\mathrm{n}=30)$. Samples 23 and 24 were their top picks (low yellow color; milk fat, cooked flavors). A salty taste was preferred over unsalted butter. Stale-flavored butters were least preferred by these consumers, below vegetable oil spreads. Consumers in segment $5(\mathrm{n}=31)$ liked salted butters. They generally liked all butter flavors (cooked, milk fat, grassy, mothball, and stale) as well as the salty taste. Vegetable oil spreads were not well liked, and unsalted butter was less well liked than vegetable oil spreads.

Across all segments, texture liking trends generally reflected overall liking results (results not shown). Consumers in segment 2 ("margarine lovers") rated both vegetable oil spreads (products 28 and 29) as their favorites in terms of texture. Although texture is an issue of importance to many consumers, the products in this study were tempered to more clearly distinguish flavor differences; thus, the textures of some of the samples 
may not have accurately depicted the texture directly from refrigerated storage or how some consumers would temper products prior to use.

Consumption trends (from focus groups and consumer acceptance testing) suggested that butter and margarine use separates consumers into 3 categories: the majority-those who use both butter and margarines or spreads, a smaller portion who use only butter, and a smaller segment who use margarines or spreads exclusively. The latter consumer group was not evaluated in this study. Butter-only and butter + margarine consumers could be further divided into 5 segments. The largest number of butter-only users fell into the "traditional" butter-lover category (segment 1). The butter + margarine consumers were distributed throughout the 5 segments, with the largest percentage (27\%) falling into segment 2 , the "margarine-lover" category. This left more than $70 \%$ of butter + margarine consumers in the other categories, indicating that although they consumed margarines and spreads, they liked butter better. With the preferred taste and desirable natural image of butter, the latter group of consumers may represent an opportunity for manufacturers to increase butter purchase and use.

\section{CONCLUSIONS}

Butter was viewed by most consumers as a tasty and natural product. Factors that influenced their purchase decision were different for butter-only users and butter + margarine consumers. Acceptance of butter and spreads differed across consumer segments and was based on many characteristics, with specific segments preferring specific butter and spread flavor profiles.

\section{ACKNOWLEDGMENTS}

The authors gratefully acknowledge the participation of the descriptive panelists in this study. This research was funded in part by the California Dairy Research Foundation. The participation of California Dairies, Inc. and Land O'Lakes, Inc. is gratefully acknowledged. Paper number FSR 07-05 of the journal series of the Department of Food Science, North Carolina State University. The use of trade names implies neither endorsement nor lack of endorsement by those not mentioned.

\section{REFERENCES}

Avramis, C. A., H. Wang, B. W. McBride, T. C. Wright, and A. R. Hill. 2003. Physical and processing properties of milk, butter, and Cheddar cheese from cows fed supplemental fish meal. J. Dairy Sci. 86:2568-2576.

Banfield, J. D., and A. E. Raftery. 1993. Model-based Gaussian and non-Gaussian clustering. Biometrics 49:803-821.

Biasioli, F., F. Gasperi, E. Aprea, I. Endrizzi, V. Framondino, F. Marini, D. Mott, and T. D. Mark. 2006. Correlation of PTR-MS spectral fingerprints with sensory characterisation of flavour and odour profile of 'Trentingrana' cheese. Food Qual. Pref. 17:63-75.

Bobe, G., E. G. Hammond, A. E. Freeman, G. L. Lindberg, and D. C. Beitz. 2003. Texture of butter from cows with different milk fatty acid compositions. J. Dairy Sci. 86:3122-3127.

Carunchia Whetstine, M. E., Y. Karagul-Yuceer, Y. K. Avsar, and M. A. Drake. 2003. Identification and quantification of character aroma components in fresh Chevre-style goat cheese. J. Food Sci. 68:2441-2447.

Chen, S., G. Bobe, S. Zimmerman, E. G. Hammond, C. M. Luhman, T. D. Boylston, A. E. Freeman, and D. C. Beitz. 2004. Physical and sensory properties of dairy products from cows with various milk fatty acid compositions. J. Agric. Food Chem. 52:3422-3428.

Chiu, T., D. Fang, J. Cheng, Y. Wang, and C. Jeris. 2001. A robust and scalable clustering algorithm for mixed type attributes in large database environment. Pages 263-268 in Proc. 7th ACM SIGKDD Int. Conf. on Knowledge Discovery and Data Mining (KDD-2001), San Francisco, CA. F. Provost and R. Srikant, ed. The Association for Computing Machinery, New York, NY.

Crane, F. 1993. The butter and margarine debate from the consumers' perspective. J. Food Products Mark. 1:45-51.

Drake, M., S. McIngvale, P. Gerard, K. Cadwallader, and G. Civille. 2001. Development of a descriptive language for Cheddar cheese. J. Food Sci. 66:1422-1427.

FDA. 2003. Subject: FDA Backgrounder: FDA Acts to Provide Better Information to Consumers on Trans Fats. FDA, Washington, DC. http://www.fda.gov/oc/initiatives/transfat/backgrounder.html Accessed June 20, 2006.

FDA. 2005. Subject: Requirements for Specific Standardized Margarine-2005 Revision. Code of Federal Regulations. Title 21, Vol. 2, Sect. 166.110. FDA, Washington, DC. http://www.accessdata. fda.gov/scripts/cdrh/cfdocs/cfcfr/CFRSearch.cfm?fr=166.110 Accessed April 17, 2006.

Hawke, J., and M. Taylor. 1994. Influence on nutritional factors on the yield, composition and physical properties of milk fat. Pages 37-77 in Advanced Dairy Chemistry. Vol. 2, Lipids. P. Fox, ed. Chapman and Hall, London, UK.

Hellemann, U., H. Tuorila, A.-M. Lampi, and I. Matuszewska. 1990. Hedonic responses and attitudes related to fats used as spreads on bread. Food Qual. Pref. 2:29-38.

International Dairy Foods Association. 2005. Pages 63-71 in Dairy Facts. International Dairy Foods Association, Washington, DC.

Kim, B. H., H. Shewfelt, and C. Akoh. 2005. Sensory evaluation of butterfat-vegetable oil blend spread prepared with structured lipid containing canola oil and caprylic acid. J. Food Sci. 70:S406-S412.

Kornerup, A., and J. Wanscher. 1978. Methuen Handbook of Colour. E. Methuen, London, UK.

Martens, H., and M. Martens. 2001. Multivariate Analysis of Quality: An Introduction. John Wiley and Sons, West Sussex, UK.

McNeill, K. L., T. H. Sanders, and G. V. Civille. 2002. Descriptive analysis of commercially available creamy style peanut butters. J. Texture Stud. 17:391-414.

Meilgaard, M., G. Civille, and B. Carr. 1999. Descriptive analysis techniques. Pages 173-183 in Sensory Evaluation Techniques. M. Meilgaard, G. Civille, and B. Carr, ed. CRC Press, Boca Raton, FL.

Michicich, M., Z. Vickers, M. C. Martini, and J. B. Labat. 1999. Consumer acceptance, consumption and sensory attributes of spreads made from designer fats. Food Qual. Pref. 10:147-154.

Moskowitz, H. 2001. Margarine: The drivers of liking and image. J. Texture Stud. 16:53-72.

Nickerson, S. 1995. Milk production: Factors affecting milk composition. Pages 15-17 in Milk Quality. F. Harding, ed. Blackie Academic \& Professional, London, UK.

Norwood, J. 2004. Subject: Natural Products. Agricultural Marketing Resource Center, Ames, IA. http://www.agmrc.org/NR/rdonlyres/ 61DAD87B-9BE8-41C0-8161-0391DD070917/0/naturalfoods norwood.pdf Accessed June 20, 2006.

Rohm, H., Strobl, M., Jaros, D. 1997. Butter colour affects sensory perception of spreadability. Z. Lebensm. Unters. Forsch. A, Food Res. Technol. 205:108-110. 
Schlich, P. 1995. Preference mapping: Relating consumer preferences to sensory or instrumental measurements. Pages 231-245 in Bioflavour'95: Analysis/Precursor Studies/Biotechnology. P. Etiévant and P. Schreier, ed. INRA Editions, Versailles, France.

SPSS, Inc. 2001. Subject: The SPSS TwoStep Cluster Component: A Scalable Component Enabling More Efficient Customer Segmentation. SPSS, Inc., Chicago, IL. http://www.spss.ch/upload/1122 644952_The\%20SPSS\%20TwoStep\%20Cluster\%20Component. pdf Accessed June 22, 2006.

Thompson, J. L., M. A. Drake, K. Lopetchararat, and M. D. Yates. 2004. Preference mapping of commercial chocolate milks. J. Food Sci. 69:S407-S413.

USDA. 1989. Subject: United States Standards for Grades of Butter. Section 58.2621. USDA, Washington, DC. http://www.ams.usda.gov/standards/Butter.pdf Accessed Apr. 17, 2006.
USDA-ERS (USDA Economic Research Service). 2006. Subject: Per capita food consumption-Fats and oils. In Food Consumption (Per Capita) Data System. USDA-ERS, Washington, DC. http:// www.ers.usda.gov/Data/FoodConsumption/spreadsheets/ fats.xls\#Margarine!a1 Accessed Apr. 17, 2006.

Wright, G. 1991. Dairy products and the consumer. Br. Food J. 91:12-15.

Young, N. D., M. A. Drake, K. Lopetcharat, and M. R. McDaniel. 2004. Preference mapping of Cheddar cheese with varying maturity levels. J. Dairy Sci. 87:11-19.

Zhang, T., R. Ramakrishnan, and M. Livny. 1996. BIRCH: An efficient data clustering method for very large databases. In Proc. 1996 ACM SIGMOD Int. Conf. on Management of Data, Quebec, Canada. H. V. Jagadish and I. S. Mumick, ed. ACM, New York, NY. 